\section{Alcohol, diabetes, and public health in the Americas}

\author{
Thomas Babor, ${ }^{1}$ Jurgen Rehm, ${ }^{2}$ David \\ Jernigan, ${ }^{3}$ Patrice Vaeth, ${ }^{4}$ Maristela \\ Monteiro, ${ }^{5}$ and Hallie Lehman ${ }^{5}$
}

Suggested citation: Babor T, Rehm J, Jernigan D, Vaeth P, Monteiro M, Lehman H. Alcohol, diabetes, and public health in the Americas. Rev Panam Salud Publica. 2012;32(2):151-5.

\section{ABSTRACT}

This article describes epidemiological evidence on the association between alcohol use and diabetes, and the implications for clinical management and public health policies in the Americas. Heavy alcohol use is a risk factor for both diabetes and poor treatment adherence, despite evidence that moderate drinking can protect against type 2 diabetes under some circumstances. The burden of disease from diabetes associated with excessive alcohol consumption warrants both clinical and public health measures. On the clinical level, research on early interventions to prevent hazardous drinking shows that new screening, brief intervention, and referral techniques are effective ways to manage hazardous drinking in primary care settings. On the population level, restrictions on alcohol marketing and other alcohol control policies reduce the frequency and intensity of alcohol consumption in at-risk populations. These policy actions are recommended within the context of the World Health Organization's global strategy to reduce the harmful use of alcohol.

Key words: alcohol drinking; diabetes mellitus; cost of illness; health promotion; Americas.

\footnotetext{
Department of Community Medicine and Health Care, University of Connecticut School of Medicine, Farmington, Connecticut, United States of America. Send correspondence to: Thomas Babor, babor@nso.uchc.edu

2 Social and Epidemiological Research Department, Centre for Addiction and Mental Health, Toronto, Ontario, Canada.

3 Department of Health, Behavior and Society, Johns Hopkins Bloomberg School of Public Health, Baltimore, Maryland, United States of America.

4 Health Promotion and Behavioral Sciences Department, University of Texas School of Public Health, Dallas Regional Campus, Dallas, Texas, United States of America.

5 Alcohol and Substance Abuse Program, Pan American Health Organization, Washington, D.C., United States of America.
}

The interaction between diabetes mellitus and alcohol consumption is complex. While regular light-tomoderate drinking may decrease the risk for diabetes, heavy drinking increases this risk $(1,2)$. Moreover, alcohol consumption, especially "binge" drinking (heavy episodic consumption), can worsen the course of the disease and influence its outcomes via a number of mechanisms. Recent meta-analyses, systematic reviews, and primary studies $(1,2)$ illustrate the multiple ways alcohol consumption can affect diabetes, and provide the basis for integrating alcohol control measures into the public health approach to diabetes prevention and management within the context of the World Health Organization (WHO) global strategy to reduce the harmful use of alcohol (3). This article describes the association between alcohol use and diabetes within the context of new conceptual and preventive developments in the management of diabetes from a public health perspective.

\section{ALCOHOL CONSUMPTION IN THE AMERICAS}

In 2004, in the Americas region, alcohol consumption ranked as the fifth leading cause of mortality (resulting in an estimated 343000 deaths) and the leading cause of disability-adjusted life years (DALYs) (years of life lost due to premature death plus years of healthy life lost due to illness and disability) (4). As a risk factor for mortality and morbidity, alcohol consumption ranks slightly above use of tobacco and six times higher than use of illicit drugs. Its relative impact is higher in the low- and middle-income countries of the region, where the rate of both alcohol consumption per capita and "binge" drinking (heavy episodic consumption, which is particularly deleterious to health and has a negative effect on disease progression) exceeds levels reported in the high-income economies (5). Table 1 provides a glossary of terms and definitions related to alcohol consumption.

\section{Interaction with diabetes}

A curvilinear (J-shaped) relationship exists between average volume of alcohol consumption and incidence of type 2 diabetes (1, 2, 6). Abstainers and heavy drinkers have a higher risk of diabetes, whereas light drinkers have the lowest risk. In a meta-analysis of epidemiological studies representing 13 cohorts, Carlsson et al. (1) reported a protective effect of moderate alcohol consumption of about $32 \%$ (relative risk $=0.72$ ). Both men and women demonstrate the same relationship, but the latter have a higher risk for diabetes at lower levels of average alcohol consumption. 
TABLE 1. Glossary of terms related to alcohol consumption used in study of association between alcohol and diabetes, Americas region, $2010^{\mathrm{a}}$

\begin{tabular}{|c|c|}
\hline Term & Definition \\
\hline $\begin{array}{l}\text { Light-to-moderate } \\
\text { drinking }\end{array}$ & $\begin{array}{l}\text { No more than two "standard" drinks (defined as single serving of beer, wine, or liquor containing approximately } 12 \mathrm{~g} \text { of } \\
\text { absolute alcohol) per day for men (or one per day, for women), and no more than } 14 \text { drinks per week for men ( } 7 \text { per } \\
\text { week for women) }\end{array}$ \\
\hline Heavy drinking & Alcohol consumption that exceeds the light-to-moderate drinking levels defined above (per day and per week) \\
\hline "Binge" drinking & Five or more drinks during a single occasion for men (or 4 or more drinks, for women) \\
\hline \multirow[t]{2}{*}{ Hazardous alcohol use } & $\begin{array}{l}\text { Pattern of drinking that carries elevated risk of harm, such as the consumption of a sufficient amount of alcohol to cause } \\
\text { mental or physical impairment }\end{array}$ \\
\hline & $\begin{array}{l}\text { Consumption of more than } 2 \text { drinks per day on average for men (or more than } 1 \text { drink per day on average for women) } \\
\text { increases the risk of a variety of health conditions }\end{array}$ \\
\hline Harmful alcohol use & $\begin{array}{l}\text { Pattern of drinking that causes harm to health, including 1) physical (physiological) damage, such as fatty liver and } \\
\text { hypertension and 2) mental (psychological) damage, such as depression related to heavy drinking }\end{array}$ \\
\hline Alcohol dependence & $\begin{array}{l}\text { Syndrome of behavioral, cognitive, and physiological symptoms that substantially reduces an individual's ability to } \\
\text { control the quantity and frequency of alcohol consumption }\end{array}$ \\
\hline Alcohol use disorders & $\begin{array}{l}\text { Harmful alcohol use and dependence, the two most prominent aspects of alcohol use disorders in the World Health } \\
\text { Organization's International Classification of Diseases (ICD) }\end{array}$ \\
\hline
\end{tabular}

a Source: Babor et al. (17).

The actual impact of average consumption seems to be mediated by heavy drinking occasions (7). As with ischemic heart disease, the protective effect is limited to light-to-moderate drinking without irregular heavy drinking occasions (8). However, the empirical evidence is not extensive, and the studies are not usually well controlled (e.g., there is no separation between lifetime abstention and former drinkers, and no control for volume when the effects of binges are assessed). In addition, studies rarely use the same measures of alcohol consumption and alcohol use disorders, making them hard to compare. With respect to heavy drinking and alcohol use disorders, the effect on incidence of diabetes seems to be detrimental overall (2). Beyond the contribution of alcohol consumption to the risk of diabetes, once the disease is established, chronic alcohol consumption may exacerbate hypoglycemia, nutritional problems, neuropathy, injuries, seizures, and other health conditions common to both diabetic patients and persons with alcohol dependence (9).

\section{Effect on diabetes prevention and management}

A small body of research indicates that alcohol consumption affects diabetes self-management (10). As with other chronic conditions requiring medication (e.g., HIV / AIDS and cystic fibrosis), with respect to diabetes, heavy drinking is related to less compliance with prescribed therapies (11) and less routine medical help-seeking behavior. The overall effect of alcohol consumption (especially heavy drinking) on the progression of diabetes is detrimental and leads to a spectrum of problematic outcomes ranging from diabetic foot ulcers (12) to death.

Alcohol also can interact with oral hypoglycemic agents commonly prescribed for diabetes in patients not requiring insulin (9). As some of these agents (chlorpropamide, glyburide, and tolbutamide) inhibit aldehyde dehydrogenase, their combination with alcohol consumption can cause disulfiram-like reactions, including tachycardia, sudden change in blood pressure, convulsions, and coma.

The role of alcohol consumption in diabetes prevention and management in the Americas is well illustrated in U.S.-Mexico border communities. In the United States, the rate of diabetes prevalence in Hispanics exceeds that of non-Hispanic whites $(11.8 \%$ versus $10.2 \%$, respectively) (13). On the U.S.-Mexico border, where $42 \%$ of the population is Hispanic (mostly of Mexican origin), prevalence is considerably higher (about 16\%) (14). Research indicates that Mexican-Americans have a high prevalence of hazardous and harmful drinking relative to other U.S. Hispanic national groups, and that the border population has higher rates of dependence than the national average (15). Although poverty, lack of education, and acculturation factors may contribute to higher rates of diabetes, evidence of associations between use of alcohol and diabetes prevention and management suggest that reducing the overall level of alcohol consumption may benefit at-risk populations such as the MexicanAmerican residents on the U.S.-Mexico border.

Implications for clinical interventions. Health care providers should routinely assess the drinking patterns of their patients, regardless of diabetic status. However, given the effects of alcohol consumption on risk of diabetes and medication compliance, it is particularly important to assess alcohol consumption among diabetic patients. When relevant, the associated diabetes-specific health risks should be addressed and patients should receive a tailored intervention to improve disease management. Through the use of simple screening technologies such as the WHO's 10-question Alcohol Use Disorders Identification Test (AUDIT), patients with hazardous and harmful alcohol 
use can be identified in primary health care settings (16). The WHO-recommended interventions depend on the AUDIT score (which can also be used as an indicator of the chance of adverse reactions from various drug therapies). For example, if patients have a very low score indicating that they essentially avoid alcohol, they are encouraged to continue to abstain from drinking. If they drink moderately and wish to continue to use alcohol, they are advised about the risks of acute doses of alcohol, which include appetite stimulation, increased triglyceride levels, and elevated blood pressure. Moderately drinking patients are encouraged to 1) not exceed a standard number of drinks per week ( 7 for women, 14 for men), and never consume more than two drinks per occasion; 2) not drink on an empty stomach; and 3) avoid sweet wines and liqueurs. Patients are also encouraged to monitor their blood sugar after drinking.

For patients who exceed the recommended "lowrisk" intakes, brief interventions consisting of advice and skills training are often effective in reducing alcohol consumption back to low risk levels (16). Patients drinking at high risk levels should be shown how they compare with the general population, asked about their readiness to change their behavior, and encouraged to use simple and practical self-management skills in a brief motivational interview. Patients manifesting alcohol dependence symptoms can be referred for diagnostic assessment and alcohol treatment, as per the guidelines developed by WHO, the Pan American Health Organization (PAHO), and other health authorities. They may also be given information on how drinking interferes with the management of diabetes.

One question that often arises when considering the evidence for a protective effect of moderate alcohol consumption is whether patients who abstain from alcohol should be encouraged to drink moderately, either as a preventative measure or as a way to alter the course of the disease. Research suggests that in the daily range where alcohol consumption has protective effects for diabetes in men (22-60 g/day) and women (24-50 g/day) (2), the risk of other diseases is increased, including all-cause mortality (17).

\section{ALCOHOL PREVENTION AND CONTROL}

Alcohol control in diabetic patients supersedes primary health care services and requires a legal framework of population-based policies. Alcohol policies, many of which have proven effective in both developed and developing countries (17), are essential to decrease overall consumption and alcohol-related harm in both dependent and non-dependent individuals. The most highly recommended policies include 1) controlling access to and availability of alcoholic beverages (e.g., limiting the number and density of alcohol outlets and the days and hours of legal alcohol sales, and instituting state monopolies on the alcoholic beverage trade); 2) restricting how much and to whom alcohol can be sold (e.g., prohibiting sales to minors and intoxicated individuals); and 3) increasing prices through appropriate taxation (17). Controlling the marketing of alcoholic beverages through the regulation of advertising content, volume, placement, and health claims is another important element in creating a more supportive environment for healthy decisions related to alcohol consumption and diabetes control.

In most countries in the Americas region, alcohol policies are relatively lax and/or outdated (18). This weak policy framework has helped to create an environment where excessive drinking is commonplace. The alcohol industry takes advantage of lax alcohol policies, promoting their products heavily through targeted marketing and brand sponsorship of sporting events and other popular activities. Many countries in the region derive economic benefit from selling alcohol, leading to governmental ambivalence toward consumption and marketing regulation. Overall increases in consumption by adolescents and women, documented in many population surveys conducted in the region, parallel the strong marketing strategies directed at these groups, which are conducted without restriction or legislation. Alcohol prices are very low relative to disposable income, and alcohol is widely available (5). Several countries in the region permit the sale of alcohol without a license, effectively making it easily available to anyone, anywhere, at any time (18). Even when laws prohibiting sales to minors are in place, they are rarely enforced (15). In some countries, the consumption of "unrecorded" (illicit or informally produced) alcohol adds to an already significant per capita consumption of commercially produced beverages. Illicit markets must be better regulated through laws, regulations, and other measures.

Within the context of a relatively weak structure of public health measures directed at alcohol-related problems in the Americas, some effective practices have been applied at the national and municipal level (5). These include the use of early intervention measures (e.g., screening and brief intervention, or SBI) in primary health care; increased alcohol taxes (as implemented in Canada, Venezuela, and certain parts of the United States); municipal restrictions on the hours of legal alcohol sales (like those in Diadema, São Paulo, Brazil); controls on alcohol advertising (as in Costa Rica); drink-driving laws (Brazil, Canada, Mexico, and the United States); minimum alcohol purchase age laws (Canada, United States); and state monopolies on alcohol sales (Canada, Colombia, and the United States) (17). Given the tremendous impact of alcohol on public health, and its link to noncommunicable diseases, including diabetes, these types of population-based alcohol policies, along with targeted interventions, should be an integral part of the overall response to diabetes.

\section{ALCOHOL MARKETING AND DIABETES PREVENTION}

At least 13 longitudinal studies demonstrate that exposing youth to alcohol advertising and marketing increases the likelihood that non-drinking youth will start to drink and that those already drinking will increase their overall consumption of alcohol 
(19). Preventing young people's exposure to alcohol advertising is particularly difficult because the principal control of marketing in the Americas region is limited to the alcohol industry's own self-regulatory guidelines. In their study of the five most popular beer advertisements broadcast on Brazilian television in the summer of 2005-2006 and during the 2006 FIFA (Fédération Internationale de Football Association) World Cup games, Vendrame et al. found that the regulations most likely to be violated were Guidelines 1 and 2 of Brazil's code of marketing self-regulation, which are designed, respectively, to protect children and teenagers, and to prohibit ad content encouraging excessive and irresponsible alcoholic beverage consumption (20). The authors concluded that in this case the major beer producers had systematically violated the content guidelines of the Brazilian advertising code. Analyses conducted in the United States by the Center on Alcohol Marketing and Youth (Johns Hopkins Bloomberg School of Public Health, Baltimore, MD, USA) found that despite a voluntary standard banning alcohol advertising to audiences disproportionately below the legal drinking age of 21, in 2008, in national magazines, young people ages 12 to 20 were exposed to $10 \%$ more advertisements per person for beer and $16 \%$ more advertisements per person for "alcopops" 6 than adults age 21 and above (21). There is also evidence that the ratio of youth-to-adult exposure to alcohol advertising among women is higher than the ratio between boys and men. In the United States, youth exposure to alcohol advertising via television has grown dramatically in the past decade, from an average of 216 ads per year in 2001 to 366 ads per year in 2009 (22).

In response to the growing concern over obesity and other diet-related health problems, an increasing number of advertising campaigns are claiming that alcoholic beverages are natural or "organic," that they contain all-natural additives with desirable features such as "mystical healing powers" (e.g. see Four Loko (USA) at http://www.drinkfour.com/products), that they are the perfect accompaniment to a physical fitness regimen, and/or that they are diet drinks. Many of these types of ads are aimed at women. For example, several beer companies developed low calorie or "light beers." Light beers vary widely in their alcohol content by volume (ABV) and despite claims that "one can have a light beer that doesn't build a beer belly but still gets you buzzed" (http://www.womenshealthmag.com/ weight-loss/best-light-beers), low calorie beers which have less ABV are unlikely to give a "buzz" with a single unit, and drinking 2 or more will build up the calorie intake too. These tactics skirt industry-sponsored regulations restricting health claims in alcohol advertising and are likely to confuse consumers (particularly young people), including those with diabetes, about the complex relationship between alcohol and health. Lobbying and the dissemination of industry-favorable policy reports by industry stakeholders further un-

A combination of the words alcohol and pop meaning "flavored alcoholic beverages." dercut public health efforts to provide clear messages about alcohol and health.

While $48 \%$ of WHO member countries require some type of health warning labels (HWLs) on alcohol advertising, this form of public health response to advertiser claims competes with billions of dollars in alcohol advertising. The Agreement on Trade-Related Aspects of Intellectual Property Rights (TRIPs) signed in 1994 and administered by the World Trade Organization has been used by tobacco companies to challenge national regulations requiring stronger warnings. This agreement offers another potential barrier to national efforts to counter health and other functional claims in alcohol advertising.

\section{Conclusions}

The burden of alcohol use and its impact on diabetes is exacerbated by the lack of a public health response to the harmful use of alcohol in the Americas region. Despite the fact that alcohol makes a significant contribution to the overall burden of various noncommunicable diseases, alcohol misuse among those diagnosed with diabetes is often not addressed at all, or addressed only in clinical settings. In addition, alcohol availability is high and increasing, prices are low, enforcement of existing laws is often minimal, and the promotion of alcohol consumption is widespread through marketing strategies that are either not regulated or only self-regulated by the alcohol industry. Without comparable attention to the control of alcohol availability, pricing, and marketing at the population level, the contribution of alcohol to early onset of diabetes, poor compliance with treatment, and a more severe course is likely to continue unabated. Combining universal population measures with targeted interventions can help to prevent a substantial burden of disease in high-risk diabetic populations. At the clinical level, early intervention using new screening, brief intervention, and referral techniques is an effective way to manage hazardous drinking by diabetic patients in primary care settings. At the population level, restrictions on alcohol availability and marketing combined with higher alcohol taxes can reduce the frequency and intensity of alcohol consumption in at-risk populations. These policy actions are recommended within the context of the $\mathrm{WHO}$ 's global strategy to reduce the harmful use of alcohol.

\section{RESUMEN}

\section{Alcohol, diabetes y salud pública en las Américas}

Este artículo describe las pruebas epidemiológicas de la asociación entre el consumo de alcohol y la diabetes, así como sus implicaciones para el manejo clínico y las políticas de salud pública en las Américas. Aunque existe evidencia de que, en determinadas circunstancias, el consumo moderado de alcohol puede proteger contra la diabetes de tipo 
2, su consumo excesivo es un factor de riesgo tanto para la diabetes como para la adherencia terapéutica deficiente. La carga de morbilidad de la diabetes asociada con el consumo excesivo de alcohol requiere la adopción de medidas tanto clínicas como de salud pública. En el ámbito clínico, la investigación sobre intervenciones tempranas para prevenir el consumo de riesgo muestra que las nuevas técnicas de tamizaje, intervención breve y remisión son formas eficaces de abordar el consumo de riesgo en atención primaria. En el ámbito poblacional, las restricciones en la venta y otras politicas de control reducen la frecuencia y la intensidad del consumo de alcohol en las poblaciones en riesgo. Estas acciones de politica se recomiendan en el contexto de la estrategia mundial de la Organización Mundial de la Salud para reducir el consumo de alcohol nocivo.

Palabras clave: consumo de bebidas alcohólicas; diabetes mellitus; costo de enfermedad; promoción de la salud; Américas.

\section{REFERENCES}

1. Carlsson S, Hammar N, Grill V. Alcohol consumption and type 2 diabetes Meta-analysis of epidemiological studies indicates a U-shaped relationship. Diabetologia. 2005;48(6):1051-4.

2. Baliunas DO, Taylor BJ, Irving H, Roerecke M, Patra J, Mohapatra S, et al. Alcohol as a risk factor for type 2 diabetes: systematic review and meta-analysis. Diabetes Care. 2009;32(11):2123-32.

3. World Health Organization. Global strategy to reduce the harmful use of alcohol. Geneva: WHO; 2010. (EB126/ 2010/REC/2).

4. World Health Organization. Global health risks. Geneva: WHO; 2009.

5. Monteiro MG. Alcohol and public health in the Americas: a case for action. Washington: Pan American Health Organization; 2007.

6. Koppes LL, Dekker JM, Hendriks HF Bouter LM, Heine RJ. Moderate alcohol consumption lowers the risk of type 2 diabetes: a meta-analysis of prospective observational studies. Diabetes Care. 2005;28(3):719-25.

7. Kerr WC, Ye Y. Relationship of lifecourse drinking patterns to diabetes, heart problems, and hypertension among those 40 and older in the 2005 U.S. National Alcohol Survey. J Stud Alcohol Drugs. 2010;71(4):515-25.

8. Carlsson S, Hammar N, Grill V, Kaprio J. Alcohol consumption and the incidence of type 2 diabetes: a 20-year follow-up of the Finnish twin cohort study. Diabetes Care. 2003;26(10):2785-90.

9. Brick J, Wallen MC, Lorman WJ. Interaction of alcohol with medications and other drugs. In: Brick J, editor. Hand- book of the medical consequences of alcohol and drug abuse. 2nd ed. New York: Haworth Press; 2008. Pp. 529-65.

10. Ahmed AT, Karter AJ, Liu J. Alcohol consumption is inversely associated with adherence to diabetes self-care behaviours. Diabet Med. 2006;23(7):795-802.

11. Johnson KH, Bazargan M, Bing EG. Alcohol consumption and compliance among inner-city minority patients with type 2 diabetes mellitus. Arch Fam Med. 2000;9(10):964-70.

12. Altenburg N, Joraschky P, Barthel A, Bittner A, Pöhlmann K, Rietzsch H, et al. Alcohol consumption and other psychosocial conditions as important factors in the development of diabetic foot ulcers. Diabet Med. 2011;28(2):168-74.

13. National Institute of Diabetes and Digestive and Kidney Diseases (US). National diabetes statistics, 2011 [fact sheet]. Bethesda, MD: U.S. Department of Health and Human Services, National Institutes of Health; c2011. Available from: http://diabetes.niddk.nih.gov/ $\mathrm{dm} /$ pubs/statistics/ Accessed 12 July 2012.

14. Caetano $R$, Ramisetty-Mikler $S$ Rodriguez LA. The Hispanic Americans Baseline Alcohol Survey (HABLAS): rates and predictors of alcohol abuse and dependence across Hispanic national groups. J Stud Alcohol Drugs. 2008;69(3):441-8.

15. Caetano R, Ramisetty-Mikler S, Wallisch LS, McGrath C, Spence RT. Acculturation, drinking, and alcohol abuse and dependence among Hispanics in the Texas-Mexico border. Alcohol Clin Exp Res. 2008;32(2):314-21.
16. Babor TF, Higgins-Biddle JC, Saunders JB, Monteiro MG. AUDIT-the Alcohol Use Disorders Identification Test: guidelines for use in primary care. 2nd ed. Geneva: World Health Organization; 2001.

17. Babor $\mathrm{T}$, Caetano $\mathrm{R}$, Casswell $\mathrm{S}$, Edwards G, Giesbrecht N, Graham K, et al. Alcohol: no ordinary commodity: research and public policy. 2nd ed. Oxford: Oxford University Press; 2010.

18. Babor TF, Caetano R. Evidence-based alcohol policy in the Americas: strengths, weaknesses, and future challenges. Rev Panam Salud Publica. 2005;18(4-5): 327-37.

19. Anderson P, de Bruijn A, Angus K, Gordon R, Hastings G. Impact of alcohol advertising and media exposure on adolescent alcohol use: a systematic review of longitudinal studies. Alcohol Alcohol. 2009;44(3):229-43.

20. Vendrame A, Pinsky I, e Silva RS, Babor T. Assessment of self-regulatory code violations in Brazilian television beer advertisements. J Stud Alcohol Drugs. 2010;71(3):445-51.

21. Center on Alcohol Marketing and Youth (US). Youth exposure to alcohol advertising in national magazines, 2001-2008. Baltimore: CAMY; 2010.

22. Center on Alcohol Marketing and Youth (US). Youth exposure to alcohol advertising on television, 2001-2009. Baltimore: CAMY; 2010.

Manuscript received on 22 July 2011. Revised version accepted for publication on 22 June 2012. 